Fecha de recepción: diciembre 2012 Fecha de aceptación: septiembre 2013 Versión final: septiembre 2014

\section{Notas para un diseño negativo. Arte y política en el proceso de conformación del campo del Diseño Gráfico}

Octavio Mercado G. *

\begin{abstract}
Resumen: El diseño ocupa un lugar relevante dentro de la producción cultural contemporánea; el entorno social en su conjunto está articulado a partir de objetos artificiales: productos de diseño. La profusión del producto de diseño, obliga a reflexionar acerca de la capacidad del diseñador como individuo, para incidir dentro de su entorno, a partir de la generación de productos estéticos que, en su vínculo con la función, alcanzan la posibilidad del cambio social a través del cambio en los individuos. De alguna manera, gracias a su propia estructura, el diseño se convierte en una disciplina donde tiene lugar la materialización de las aspiraciones de la vanguardia artística: la fusión de arte y vida. Si el diseño es capaz de asumir las posibilidades que tiene para la construcción de usuarios críticos, potencia su capacidad y permite que el diseñador sea un agente del cambio social a partir de un diseño negativo y no únicamente reafirme el orden existente mediante un diseño positivo.
\end{abstract}

Palabras clave: Arte - Bourdieu - campo - diseñador - diseño - habitus - resistencia - revolución - teoría crítica.

[Resúmenes en inglés y portugués en las páginas 49-50]

${ }^{(*)}$ Diseñador de la Comunicación Gráfica (UAM-X). Maestro en Creatividad para el Diseño (EDINBA). Maestro en Historia del ARTE (UNAM). Actualmente escribe el trabajo de tesis para obtener el grado de Doctor en Historia del Arte (UNAM). Es Profesor Asociado de tiempo completo en la Universidad Autónoma Metropolitana, Unidad Cuajimalpa.

El proceso de construcción del campo del diseño es resultado de una serie de cambios que tuvieron lugar a lo largo del siglo XX, tanto en las formas de producción, como en los lenguajes artísticos. Entendido a partir de la suma de estas esferas, podemos asumir su condición esencial de unir forma y función, como la puesta en práctica de las aspiraciones de las vanguardias artísticas de fusionar arte y vida cotidiana. La genealogía misma de la profesión, y las fechas significativas en su desarrollo histórico, permiten establecer conexiones entre el diseño y las prácticas artísticas al grado de que, una parte de la historiografía del arte reconoce a la Bauhaus, piedra fundamental de la disciplina, como movimiento relacionado con el espíritu vanguardista de dadaístas y surrealistas en tanto ambición por transformar al mundo desde la producción estética. 
Particularmente en lo que respecta al diseño gráfico, su orientación hacia la generación de imágenes, ha permitido que, bajo el espíritu de los estudios culturales y visuales, se pueda pensar en una historia de la imagen, que conjunte las formas de representación independientemente del campo de producción cultural en el que tuvieron lugar mezclando, a veces en forma exagerada objetos artísticos y productos de diseño, a pesar de que se trata de artefactos culturales que, al provenir de espacios diferentes, han sido construidos siguiendo normas y objetivos totalmente distintos.

Las prácticas culturales tienden a generar ciertos espacios específicos, provistos de una lógica interna y de ciertas reglas y asignación de funciones hacia su interior. El sociólogo francés, Pierre Bourdieu, llamó Campos a estos espacios sociales en los que tiene lugar la disputa por formas específicas de capital, y caracterizados por la existencia de agentes que buscan dichas formas de capital.

En el caso del diseño gráfico, podemos hablar, en este sentido, de la existencia de un campo propio, configurado a partir de la existencia de límites disciplinares que, con relativa claridad, nos permiten marcar cual es su ámbito específico de desenvolvimiento, y de qué manera podemos diferenciarlo de otras prácticas de producción visual, como podría ser el caso de las artes visuales.

La construcción de un campo propio del diseño gráfico, implica no solamente el reconocimiento de una cierta historia y de un proceso de construcción propio, sino que nos obliga a pensar en él en términos de su conformación institucional y, ante todo, de la manera en que los agentes que en él participan, están marcados por la existencia de un Habitus particular.

\section{El Habitus y los campos de producción cultural}

Bourdieu llama Habitus a la ubicación diferenciada de los distintos agentes participantes dentro del campo (en el caso del diseño gráfico: diseñadores, impresores, consumidores, etc. Todos quienes intervienen en la producción y/o consumo de diseño), esta ubicación es determinada a partir de la manera en que los agentes logran acumular capital cultural y económico, mismos que condicionan la manera en la que serán percibidos los sucesos que tengan lugar dentro del campo. Así, el establecimiento de un Habitus de diseñador, marca la percepción de los hechos ocurridos dentro del campo, la forma en que tienen lugar los intercambios de capital simbólico, y las vías en que es posible establecer estrategias para su acumulación.

El ejemplo que brinda Bourdieu sobre el Habitus del filólogo en su ensayo Algunas propiedades sobre los campos, nos permite reflexionar al respecto:

... es a la vez, un oficio, un cúmulo de técnicas, de referencias, un conjunto de creencias, como la propensión de conceder tanta importancia a las notas al pie como al texto, propiedades que dependen de la historia (nacional e internacional) de la disciplina, de su posición (intermedia) en la jerarquía de las disciplinas y que son a la vez condición para que funcione el campo y el producto de dicho funcionamiento (Bourdieu, 2002: 120). 
Podemos pensar, en un sentido análogo, que este Habitus de diseñador es la herramienta cognitiva que permite al profesional detectar las particularidades, tanto formales como materiales de los productos de diseño y establecer valoraciones al respecto. Bourdieu señala que aquello que denominamos como el gusto es, en última instancia, una determinación realizada a partir del Habitus. Es decir, que nuestro sistema de preferencias culturales, que determina aquello que aceptamos o lo que rechazamos, está marcado por nuestra ubicación dentro de campos culturales específicos. La manera en la que ciertos productos culturales se inscriben en el gusto de un grupo social determinado -enlazado por su actividad productiva- es el testimonio de la operación de estas coordenadas que cruzan lo económico y lo cultural. Dicho cruce está afectado por las condiciones históricas, en tanto factores contextuales -externos al campo-que terminan por incidir de una u otra manera en el comportamiento de sus agentes y determinando -con las variaciones en el transcurrir temporal- cambios en el gusto y la moda. En Razones Prácticas, el mismo Bourdieu intenta el ejercicio de trazar un mapa de gustos y afinidades culturales en el espectro social a partir de las distintas acumulaciones de capital cultural y económico, observando, por ejemplo que es un grupo determinado el que tiene por afición el tocar el acordeón o que un segmento específico acostumbra beber regularmente vino espumoso (Bourdieu, 1997: 13). Podemos pensar que ocurre lo mismo, tanto con los objetos artísticos como con los productos de diseño.

Lo que en un momento es válido para un grupo social, en otra época será posiblemente rechazado, no solo en virtud de su obsolescencia en términos de resolución técnica, sino de su falta de adecuación a los parámetros normativos vigentes que seleccionan y descartan estilos, tendencias y materiales. Dichos parámetros son establecidos desde los propios campos de producción cultural, en donde se fijan los criterios de legitimidad que permiten la obtención del capital específico del campo, fortaleciendo su autonomía a la vez que marcando una posible incidencia en la sociedad en términos de la construcción de un imaginario de prácticas legítimas.

El campo así planteado, es un territorio en el que se dirimen los conflictos que dan sentido a las disciplinas. Hablando del campo artístico, por ejemplo, resulta un lugar común mencionar que el gran tema del arte contemporáneo es el arte mismo. La noción presentada por Bourdieu, permite asumir este problema a partir de la existencia de discusiones que tienen valor y validez, únicamente en el espacio específico de las artes, que está conformado por los artistas, los críticos, los marchands, los curadores, etc., cada uno de ellos, poseedor de un hábitus generado a partir de su ubicación en el campo, y de las consecuentes relaciones que es capaz de establecer con el resto de los agentes participantes. El campo nos permite así abordar una de las condiciones de mayor peso desde el establecimiento de la noción misma de Arte Moderno: la producción artística entendida como arte por el arte, la que desde este enfoque constituiría una producción orientada hacia el propio campo, remarcando el carácter autónomo de este, en donde es posible articular discusiones que están ligadas casi exclusivamente con su propia historicidad, totalmente alejadas de su inserción en la más amplia esfera de lo social, la que a su vez queda totalmente desconectada de las dinámicas internas de ese singular espacio de producción, separando al público no enterado, de la posibilidad de establecer algún mecanismo de apropiación de la obra de arte. 
Para la ilustrar la idea, podemos plantear a manera de ejemplo, la existencia de un campo literario en el que, escritores, editores, impresores, críticos literarios, editoriales, instituciones educativas y asociaciones o grupos de escritores entre otros, establecen un juego de poder en la búsqueda de un capital simbólico específico (que podríamos traducir como una forma de prestigio y reconocimiento) que es válido y tiene algún sentido solamente en el interior del campo, sin que los individuos fuera de él tengan posibilidad de apreciar en su totalidad las acumulaciones de capital. Se trata, en última instancia, de algo que guarda semejanza con lo que ocurre con un juego de mesa, donde los roles, las reglas y los objetivos son meramente simbólicos, y solamente tienen sentido para los jugadores, quienes validan el juego con su participación; frente a ellos, el individuo que va pasando, solamente alcanza a percibir que allí está ocurriendo una escenificación en la que participan individuos jugando papeles distintos, pero muy difícilmente podrá arribar a la comprensión de las reglas y de la importancia del juego a menos que comience a jugarlo (para lo cual, tiene que estar en disposición de hacerlo y de legitimar las reglas establecidas). Lo específico del capital en juego, y el hecho de que no necesariamente tiene un valor real, sino que se trata en muchos casos de un valor meramente simbólico propio del campo, obstaculiza la posibilidad de hacer una transferencia total del capital de un campo hacia otro (del campo literario al campo artístico, por ejemplo1). Este capital, permite además, dotar de legitimidad a su poseedor en tanto es producto del consenso entre los agentes, y permite por lo mismo, que todos se hagan de él en alguna medida en tanto forman parte del campo. Su reproducción histórica y trascendencia es posible a través de las instituciones, particularmente de la escuela y del seno familiar, en donde se establecen valores que dan mayor mérito a todo aquello relacionado con quienes detentan el capital específico, legitimando así a sus poseedores. Toma forma por este camino, un peculiar proceso que afecta a los objetos producidos dentro del campo que permite el reconocimiento de ellos en tanto obras de arte, sentando las bases para su posterior jerarquización al establecer un criterio de legitimidad en la medida en que son susceptibles de ser enlazados con la tradición y la historia que son reproducidas desde los espacios institucionales, por la crítica en un primer momento y posteriormente, por el resto de los agentes del campo, notablemente entre ellos, por las instituciones educativas.

La relación entre las distintas clases de capital que establece Bourdieu, le permiten marcar diferentes formas de poder y reconocimiento, vinculadas entre sí, pero alcanzables por distintas vías. Se habla así, no solamente de Capital Económico, sino de Capital simbólico, Capital Social y tres formas de Capital Cultural: Incorporado (el que ya es parte del hábitus, en relación con aquello que llamamos Cultura general), Objetivado (los bienes culturales, que pueden ser intercambiados como mercancías sin que ello implique la transmisión de los medios de apropiación del capital cultural, es decir, se puede comprar o vender una obra de arte, aceptando que es algo valioso, sin que ello implique que se entienda de donde proviene ese valor) e Institucional (el que es producido y avalado por las instituciones, como los títulos académicos o los premios y reconocimientos).

El campo está marcado por la disputa del capital simbólico, específico del campo, entre sus participantes, agentes que se comportan de acuerdo, no solo a su condición social, condicionada por el capital económico, sino también a partir de su capital cultural, y de la manera en la que estos dos elementos permiten establecer en buena medida su ubica- 
ción dentro del campo, el hábitus resultante. Dado que capital económico y cultural se convierten en los ejes que ayudan a localizar las disposiciones de los agentes, es posible, y de hecho Bourdieu lo plantea en Razones Prácticas (Bourdieu, 1997), el establecimiento y la justificación de las semejanzas tanto en el comportamiento como en el pensamiento de los actores sociales que comparten un habitus semejante, las uniformidades al interior del campo, tanto entre los artistas como entre la crítica o entre en el público (entendidas precisamente, a partir de una posición compartida por cada uno de esos agentes dentro del campo) son el resultado de esto, pero lo son también, con mayor importancia, las semejanzas y diferencias que permiten agrupar en bloques distintos, a quienes se hallan dentro y fuera del campo, en el caso del campo artístico, a quienes consumen alta cultura y a quienes consumen cultura de masas, distinguidos entre sí por su adscripción a sistemas distintos de prácticas culturales.

\section{El campo del diseño}

$\mathrm{Al}$ establecer discusiones históricas sobre el diseño gráfico, revisando los procesos de conformación del campo, es común poner el acento en la fuerza de ciertos antecedentes, representados por prácticas que si bien son previas al establecimiento formal de la actividad como práctica profesional legítima, permitieron el surgimiento de su campo disciplinario. Actividades como la edición de libros, la impresión, la tipografía, la ilustración, son ejemplos de las maneras en que distintos quehaceres específicos, vigentes incluso desde mucho antes de los procesos de industrialización, permitieron construir un acervo de prácticas formales aplicadas a la producción que, sin embargo, carecían aún de la visión de conjunto que permitiera llamarles diseño.

En el caso particular de México, el proceso de desarrollo del diseño gráfico como disciplina no solamente a nivel de saber técnico sino como campo para la producción y la reflexión, se ha ido consolidando en las últimas décadas, a partir de las necesidades de una sociedad industrializada que requiere con una fuerza cada vez mayor, de la producción de mensajes comunicativos al alcance de un público masificado.

Si bien resultaría ocioso disputar la visión canónica, que sitúa el surgimiento a nivel global del diseño como disciplina en la Bauhaus de Weimar durante el primer cuarto del siglo $\mathrm{XX}$, es preciso acotar que, el comienzo de la especialidad y la formulación de sus bases y límites, si bien constituyen la primera piedra en la construcción, no establecen de manera alguna, la existencia plena de un campo de diseño, o de una noción claramente aceptada por el público no especializado. Este es un proceso que requiere de un transcurrir mucho más pausado, y en el que intervendrán múltiples factores.

El surgimiento del campo está en plena relación con el proceso de institucionalización, de conformación de los espacios establecidos y legitimados desde los cuales se fortalece la producción de capital simbólico: las instituciones reguladoras, las asociaciones profesionales y las escuelas de diseño. Es precisamente desde estos centros de poder institucional que se establece la normatividad del campo, la manera en que ciertas prácticas resultan válidas, mientras que otras son descartadas por no ajustarse a la norma vigente. 
Llevando el ejemplo que Bourdieu aplica sobre la filosofía (Bourdieu, 2002: 125) al caso del diseño, podemos decir que ser diseñador es dominar lo necesario de la historia y la práctica del diseño, como para saber conducirse como diseñador dentro del campo del diseño.

Si bien es justamente el surgimiento de una Escuela de Diseño, la Bauhaus, en 1919, lo que nos permite situar el inicio de la disciplina por abrir un primer espacio donde tiene lugar la enseñanza de una serie de habilidades y conocimientos que en conjunto permiten su delimitación como diseño; será hasta la posterior difusión y estandarización del concepto de Diseño, que sea posible hablar en forma de un campo del diseño, es decir, esto tiene lugar hasta el momento en que ocurre una suerte de acumulación originaria de capital simbólico, posible por la manera en la que las nacientes instituciones van sancionando la producción de diseño, ya que una de las primeras necesidades del campo, es estar en posibilidad de señalar que es un buen diseño y separarlo de los malos, para lo cual, es preciso fijar criterios y valoraciones, estándares al respecto.

Dentro de la argumentación que estamos siguiendo, es preciso señalar el hecho significativo de que el surgimiento de la Bauhaus permite formular una disciplina que, desde sus orígenes, no se desprende de estrategias de transformación social herederas del Werkbund (y afectadas, hasta cierto punto, tanto por las ideas de William Morris o John Ruskin, como por el constructivismo soviético en operación durante la época que persigue la funcionalización de la actividad estética al servicio del proceso revolucionario). Esta relación con el cambio social, se aleja radicalmente de la representación social que se tiene del diseño fuera del campo, donde se le relaciona habitualmente con la publicidad y la articulación de mensajes que reafirmen el orden establecido, es decir, de lo que la tradición frankfurtiana describe como Cultura afirmativa. No podemos olvidar que: "The Bauhaus product was not to be an artist in the romanticized sense of the individual "shaper-offorms" but a fairly anonymous, communal worker" (Raleigh, 1968: 287).

Estos trabajadores comunales, son formados teniendo en mente la resolución formal de los problemas, en la búsqueda de soluciones con la mayor simplicidad posible, y donde el valor estético esté dado por la eficacia en la función. Esta orientación, tiene un enorme peso de la influencia ejercida por De Stijl a través de Teho Van Doesburg y Piet Mondrian en los primeros años de la escuela.

Las tensiones están fundadas en el intento de conciliar arte y función, forma estética y eficacia; tanto el emplazamiento como las implicaciones que los objetos de diseño tienen en la práctica cotidiana no parecen ser una preocupación presente ni en Weimar, ni en Dassau, ni en la sucesora Ulm o incluso en esa heredera lejana que es el Black Mountain College. En todos estos casos, las discusiones teóricas en el diseño se orientan -convirtiendo así a la disciplina, en cierta medida a la puesta en práctica de ello-a la conciliación ente forma y función.

Producto de lo anterior, la mayor parte de las visiones que el campo arroja hacia su interior se han conducido también en el olvido de esta posible genealogía que permitiría asumir al diseño como una forma de acción y participación en el cambio social no solamente en términos de Responsabilidad Social, sino incluso, de una forma de operación que explícita o implícitamente, pueda o bien formar parte de los mecanismos de comunicación de los agentes de cambio o, promover actitudes en el espectador que conduzcan a hacerlo 
consciente de la forma en que los mecanismos de comunicación poseen formas de articulación lingüística a partir de la utilización de un código propio lleno de convenciones que el espectador lee de manera inconsciente. La forma en que, desde las artes se generan estrategias críticas, puede ser ilustrativa de alguna forma de realizar diseño para el cambio social, en la posibilidad de visibilizar el código utilizado para permitir que el espectador cuestione al medio utilizado y no únicamente perciba el mensaje de forma acrítica. Un ejemplo de esta estrategia lo encontramos, dentro de la cultura de masas, en el funcionamiento del cine de arte, particularmente en movimientos como Dogma 95 o directores como Jean-Luc Godard, quienes persiguen el cuestionamiento de la puesta en escena y la ruptura consciente de la diégesis como formas de que el espectador cinematográfico tenga claro que se encuentra frente a una película y que, independientemente del curso que siga la historia que está presenciando, está sujeto a la manipulación de un director, quien toma las decisiones respecto a la narración que se le está contando.

La investigación sobre la teoría del diseño, permite otro camino, que ha cobrado relevancia en tiempos recientes, ocupándose, desde un inicio, de lidiar con la tensión entre forma y función, propuesta estética y utilidad, siguiendo una de las maneras en que se piensa sobre la historia de la imagen (Shiner, 2004) no solamente en términos formales, sino a partir del estudio de las transformaciones disciplinares que convirtieron a los oficios en profesiones. Recordemos que es posible trazar una línea genealógica que permita emparentar en el mismo sentido, a partir de estas preocupaciones comunes, la separación entre artes liberales y mecánicas, presente desde la antigüedad.

La formulación del diseño gráfico como disciplina, se relaciona también con dicha posibilidad, y con la forma en que son asimilados los saberes prácticos no solamente al nivel de habilidades, sino de conocimientos necesarios para su ejecución. El tránsito de la tipografía, la impresión o la producción de carteles como saberes técnicos específicos, al concepto de diseño como espacio que cubre lo específico y abre espacio para la reflexión general sobre la relación entre los medios y la producción formal, está relacionado precisamente con la forma de organización de las artes liberales y la manera en que estas producen, durante el siglo XVIII un espacio diferenciado del de las Bellas Artes (precisamente, produciendo con ello un campo de producción cultural en el que la utilidad no es determinante). No es poco frecuente, en la actualidad, encontrar revisiones ontológicas del diseño que le adscriben a las artes liberales (Buchanan, 1992) precisamente a partir de la valoración de estos aspectos.

El aspecto de mayor relevancia de esta forma de reflexión, está en que permite el cuestionamiento, no solamente sobre la transformación de los mecanismos de producción y la modificación en las formas de representación (los estilos), sino que abre la posibilidad de poner el centro en la manera en que se transforman las prácticas y los paradigmas acerca de que es entendido por diseño en un momento y en un entorno determinado. Visiones de este tipo, nos obligan a pensar en el diseño no solamente como actividad práctica, sino en el diseñador como agente social. 


\section{Notas para un diseño negativo}

Theodor Adorno, figura central de la Escuela de Frankfurt mantuvo como dentro de su trabajo, la crítica de la cultura de masas a partir de la manera en que esta, entre otros aspectos, reafirmaba el orden social establecido, replicándolo y convirtiéndose en un freno para cualquier posible cambio al facilitar la alienación de los individuos y el consiguiente empobrecimiento cultural; centra sus ataques, hacia la forma en que las prácticas artísticas se orientan hacia una estandarización que no hace sino establecer un estilo general que, una vez que es aceptado por el común de los espectadores, es repetido ad infinitum como formula probada.

Frente a ello, como alternativa, propone la articulación de una estética negativa, que persiga la ruptura del confort alcanzado por las formas tradicionales, que no inquietan, no provocan, sino simplemente adormecen. Adorno, con una sólida formación musical, piensa en Schöenberg como ejemplo de la disonancia

Partir de la noción de que el diseñador es un agente operando en el entorno social, antes que un mero comunicador o mediador entre un cliente y un usuario, modifica por completo la manera en que debe de ser entendida la práctica del diseño, abriendo la posibilidad de potenciar la incidencia social del trabajo del diseñador no solamente en la satisfacción del usuario o en la eficacia comunicativa frente al espectador, sino en la intervención en la manera en que usuarios y espectadores se involucran con objetos e imágenes resultantes del trabajo de diseño y abandonan una actitud pasiva frente a estos, para transformarse en participantes activos del proceso de diseño.

Tendría lugar así, el establecimiento de una forma de diseño crítica, que no se detuviera únicamente en una forma de cultura afirmativa, sino que lograra establecer con eficacia un espacio en el cual fuera posible tanto la difusión de información, como la construcción de alternativas que obliguen al cuestionamiento de las estructuras establecidas. Esto implica, básicamente, pensar el diseño en función de sus implicaciones sociales, y no solo a partir de su resolución formal y la correcta utilización de códigos y lenguajes (a la manera en la que la enseñanza tradicional de la disciplina suele estar orientada). Intentos al respecto se han tratado de realizar, obteniendo una recepción irregular en la pretensión de articular una teoría del diseño como estrategia revolucionaria (Selle, 1973).

Se trata pues, de abrir la posibilidad de transformar el campo del diseño y su relación con el entorno social a partir de la reformulación del acuerdo social vigente sobre la disciplina, es decir, la respuesta a la pregunta Qué es un diseñador, rebasando la noción del productor de formas o solucionador de problemas, figuras que aún hoy se siguen manteniendo vigentes en muchos ámbitos, para darle un mayor peso a la intervención social, entendida no solamente como forma de relación con causas sociales en un sentido asistencialista, como ocurre con frecuencia con la Responsabilidad Social, sino más bien como forma de plantear el reconocimiento del lugar de la producción de diseño en el contexto social, y la forma en la que esto tiene implicaciones para la misma sociedad; impactos de distinto alcance y calibre de acuerdo a la postura del diseñador. Los intentos en este camino, tienden a quedarse en meros matices de la práctica del diseño, como lo son la noción de "Diseño Preventivo" de Buckminster Fuller o alguna forma de diseño como paliativo del 
carácter anárquico de un mundo de objetos controlados por el mercado, como lo sugiere Gui Bonsieppe (Selle, 1973: 203).

Esta forma del diseñador, se acercaría a modelos como el propuesto por Woodhouse y Patton, quienes diferencian entre un proximate desginer, concentrado en la resolución técnica y formal de los problemas de diseño con el máximo grado de detalle y un designer by society como aquel que está consciente de la participación de distintos sujetos dentro del proceso de producción y recepción del objeto de diseño (Woodhouse, Patton, 2004)

Bajo esta perspectiva, la primera acción del diseñador ha de ser, no responder a la demanda del mercado sobre un artefacto o imagen, sino cuestionar que tan adecuada resulta dicha solución para el problema presentado, de manera tal que, antes que la prefiguración de la forma, sea capaz de resolver la pertinencia de la solución propuesta. Siguiendo este camino, el diseñador es capaz de promover cambios que van desde lo más sencillo y evidente, como la reducción de desechos (en la decisión de que el problema presentado no requiere un trabajo de diseño material sino inmaterial o de servicios) hasta, en el mediano y largo plazo, modificaciones en la forma en que los individuos se relacionan con los objetos e imágenes que les rodean. Para ello, la visibilización de la manera en que tiene lugar la relación habitual entre el diseño y el usuario, resulta imprescindible, pues "La teoría social del diseño puede convertirse, por consiguiente, en una teoría asocial cuando no enuncia lo que realmente sucede: a saber, la progresiva disolución de los valores de uso a través de la relación irracional entre el usuario y el producto diseñado, la creciente alienación del hombre de su medio cósico, la fetichización de los objetos de consumo gracias a la colaboración del diseño (Selle, 1973, p. 27).

Una definición más completa del diseño, debe de tomar en cuenta, tanto los factores técnico sociales que inciden en la producción de objetos de diseño, como la manera en que dichos objetos están determinados por normas culturales -fijadas, de acuerdo a la terminología marxista, en la superestructura.

La crítica de la superestructura puede ser marcada como una de las ambiciones de esta forma de diseño, en la intención de apuntar hacia la transformación de la articulación básica de la sociedad (comenzando por develar el sometimiento habitual de la disciplina hacia los intereses sustentados desde el poder, es decir, revelando su contenido ideológico) La existencia de un componente político, permite la funcionalización de la producción visual -estética- más allá de un objetivo comercial -al que tradicionalmente está anclado el diseño. La operación del cartón político, es por ejemplo, una primera instrumentación de la práctica gráfica para la consecución de un objetivo político -o al menos, comunicacional antes que comercial-, entendiendo lo político, no como el ejercicio del poder, sino, en el sentido de Jacques Ranciere, como la tensión suscitada entre los sujetos por la visibilidad frente al poder y la resistencia de este -a través de los que Ranciere llama policía (Ranciere, 1992).

La manera en la que el desarrollo de los medios masivos de comunicación tuvo lugar, la necesidad cada vez mayor de imágenes para nutrir sus contenidos, dio pie al complemento del cartón político por la ilustración y la fotografía como formas complementarias de producción visual, relacionadas con el diseño, que ganaron espacios dentro de los medios (Margolin, 1998), así la realización de portadas para revistas, se convierte en una forma de 
participación y de toma de postura (vinculada, naturalmente, a la propia línea editorial de la publicación).

El cartel se convirtió en otra forma habitual de utilización de los recursos del diseño para la producción política durante los años sesenta en Estados Unidos. Aquí, resulta interesante el cruce entre artistas y diseñadores en la búsqueda de una estrategia para la acción política, en la coincidencia en el uso del cartel como medio, tanto por quienes desde el diseño trataban de manifestar una postura (Como Paul Davis o David Mobley) como por las prácticas artísticas. Un ejemplo de esto último está en el trabajo de los artistas organizados alrededor de la Art Workers Coalition (AWC) en los años sesenta, quienes recurrían al cartel como forma de comunicación, podríamos pensar que, en un intento por preservar la autonomía del campo, y buscar una forma de producción que tocara solamente de manera tangencial a la producción estética, como es el caso del cartel. Es decir, los artistas del AWC, al momento de establecer una postura política, no lo hicieron con las herramientas del arte, sino del diseño, porque la flexibilidad del campo del diseño, y su interrelación con el entorno social, posibilita, de mejor manera de la que puede ocurrir en el arte, la enunciación de opiniones sobre las condiciones imperantes y la posible efectividad de estas en términos de comunicabilidad hacia el público en general.

En última instancia, la posibilidad de generar un diseño negativo, que cuestione y no solamente afirme el orden social establecido, no es sino la puesta en marcha de algunas de las ideas vertidas por Walter Benjamin en dos textos básicos, uno, La obra de arte en la época de su reproductibilidad técnica, donde establece las posibilidades que los nuevos medios utilizados para la producción cultural (piensa particularmente en el cine) tienen en los procesos de cambio revolucionario, al modificar la manera en que los espectadores (sobre todo los obreros) acceden a la cultura y al entretenimiento a la vez que se relacionan con la esfera tecnológica que habrá de facilitar su trabajo permitiéndoles un mayor tiempo de ocio.

El otro texto, es El autor como productor donde, siguiendo con esta misma línea de pensamiento, plantea la forma en que los medios masivos de comunicación posibilitan una participación más activa del lector del periódico, que lo convierte en un elemento del proceso de comunicación y que termina por transformar al medio unidireccional en bidireccional, al posibilitar la intervención del lector en el material impreso.

Las nuevas tecnologías han multiplicado las posibilidades en este sentido, formando espectadores participativos, particularmente respecto a internet como medio de comunicación, lo que ha posibilitado el surgimiento de conceptos como el de internet 2.0, construidos precisamente con base en la participación de los usuarios de la red en la producción y transmisión de contenidos, rompiendo con ello, en cierta medida, la separación entre el diseñador y el espectador.

El diseñador, bajo los paradigmas tradicionales, se dirigía a los espectadores o a los consumidores; una modificación vino hacia finales del siglo pasado, cuando se comenzó a hablar de usuarios como aquellos hacia los que se dirige la práctica del diseño. La construcción de un diseñador crítico (o negativo) lleva hacia un individuo que no solamente se dirige hacia los demás, solucionando necesidades o facilitando la comunicación, sino que establece la posibilidad del diseñador como alguien que forma para transformar, que provoca al otro para hacerlo participar, llevándolo a ser, en pleno, un agente de la transformación del cambio social. 


\section{Notas}

1. Es precisamente la manera en la que el capital se desplaza entre los campos, una de las razones que nos lleva a utilizar al pensamiento bourdieauno como base para la investigación que estamos realizando. Es importante remarcar aquí que, lo que no ocurre, de acuerdo a Bourdieu, es la misma valoración del capital de un campo en otro, lo cual no evita que, la acumulación de capital específico en un campo, sirva como punto de partida para la acumulación en otro campo, como ocurre con las intervenciones en la arena política de candidatos provenientes de la cultura o el deporte, por lo general, con pobres resultados.

\section{Bibliografía}

Amir, S. (2004). Rethinking design policy in the third world, Design Issues, 20 (4). Bourdieu, P. (2002). Campo de poder, campo intelectual. Buenos Aires: Montressor. (1997). Razones prácticas. Barcelona: Anagrama.

Buchanan, R. (1992). Wicked problems in design thinking. Design issues, (2), pp. 5-21.

Margolin, V. (1998). Rebellion, Reform and revolution: American Graphic Design for Social Change, Design Issues, 5 (1), pp. 59-70.

Raleigh, H. P. (1968). Johannes Itten and the background of modern art education, Art Journal, 27 (3), pp. 284-287.

Rancire, J. (1992). Politics, Identification and subjetivization, October, 61, pp. 58-64.

Selle, G. (1973). Ideología y utopía del diseño. Traducción de Eduardo Subirats. Barcelona: Gustavo Gili.

Shiner, L. (2004). La invención del arte: una historia cultural. Barcelona: Paidós.

Woodhouse, P. (2004). Design by society, science and technology studies and the social shaping of design, Design Issues, 20 (3), pp. 1-12.

Summary: Design has an important place in contemporary cultural production; the social environment as a whole is articulated from artificial objects: the design products. The profusion of product design, compels us to think about the designer's ability as an individual to influence within their environment, from the generation of aesthetic products, its link with the function, reach the possibility of social change through change in individuals. Somehow, thanks to its structure, the design becomes a discipline which takes place materializing the aspirations of the artistic vanguard: the fusion of art and life. If design is able to assume the possibilities for building critical users, its capacity is empowered and allows the designer to be an agent of social change from a negative design, not just reaffirm the existing order by a positive design.

Keywords: Art - Bourdieu - critical theory - Design - designer - field - Habitus - resistance - revolution. 
Resumo: $\mathrm{O}$ design tem um lugar relevante na produção cultural contemporânea; o entorno social está articulado a partir de objetos artificiais: produtos de design. A profusão do produto de design impõe a reflexão sobre a capacidade do designer como indivíduo, para incidir dentro do seu entorno, a partir da geração de produtos estéticos que, no seu vínculo com a função, alcançam a possibilidade da mudança social através da mudança nos indivíduos. De algum modo, devido a sua própria estrutura, o design converte-se numa disciplina onde se materializa a vanguarda artística: a fusão arte-vida. Se o design é capaz de assumir as possibilidades que tem para a construção de usuários críticos, potencia sua capacidade e permite que o designer seja um agente da mudança social a partir de um design negativo e não unicamente reafirme a ordem existente mediante um design positivo.

Palavras chave: Arte - Bourdieu - campo - Design - designer - Habitus - resistência - revolução - teoria crítica. 